Supplement of Hydrol. Earth Syst. Sci., 24, 3077-3096, 2020

https://doi.org/10.5194/hess-24-3077-2020-supplement

(c) Author(s) 2020. This work is distributed under

the Creative Commons Attribution 4.0 License.

(c) (1)

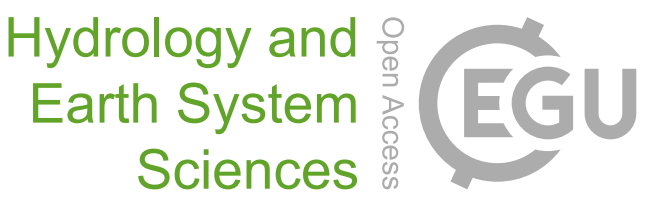

Supplement of

\title{
Future shift in winter streamflow modulated by the internal variability of climate in southern Ontario
}

Olivier Champagne et al.

Correspondence to: Olivier Champagne (champago@mcmaster.ca)

The copyright of individual parts of the supplement might differ from the CC BY 4.0 License. 
S.1 Example of geofabric using Arcpy-GSFLOW: South part of Big Creek watershed

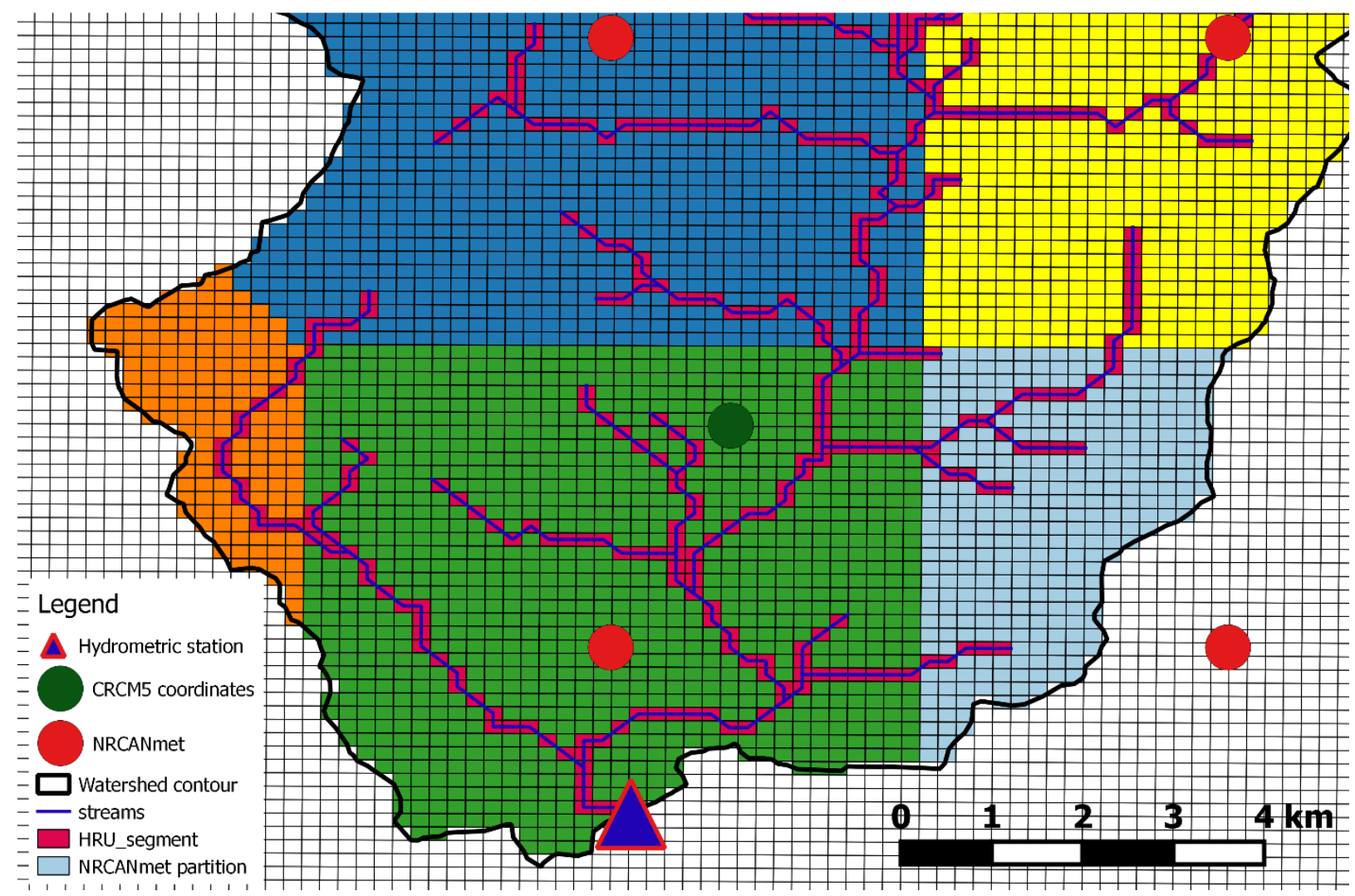

Figure S1 GRUs in the south part of Big Creek watershed. Red GRU's are directly contributing to the stream and receive water from upslope GRU's according to the cascade algorithm. The other colors separate GRU's according to the NRCANmet point they are associated with. 
S.2 Spatial variability of the main parameters estimated by Arcpy-GSFLOW
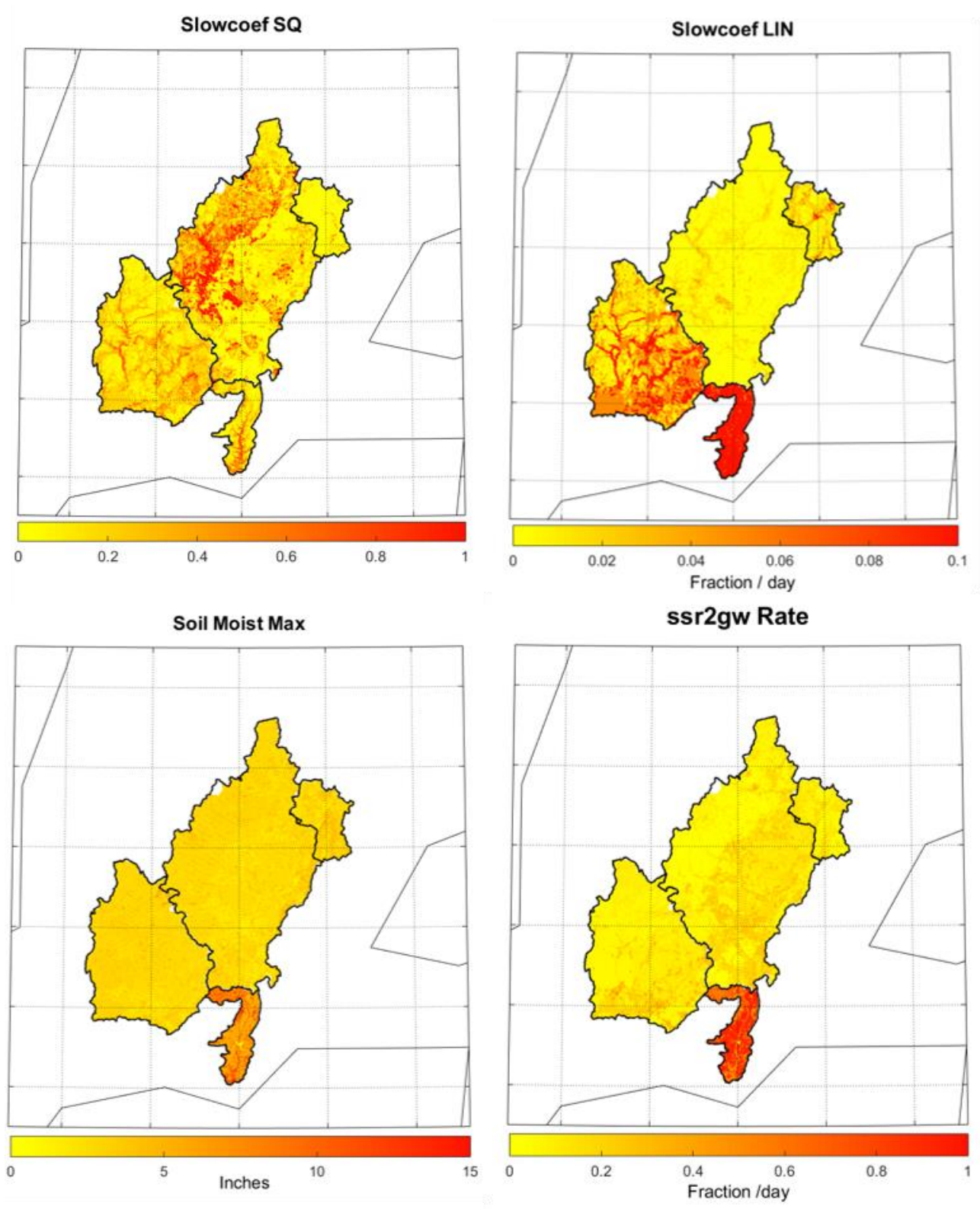

Figure S2 Spatial variability of four calibrated parameters pre-calculated using Arcpy-GSFLOW 


\section{S.3 Sensitivity analyses of the calibrated parameters in Big Creek watershed.}
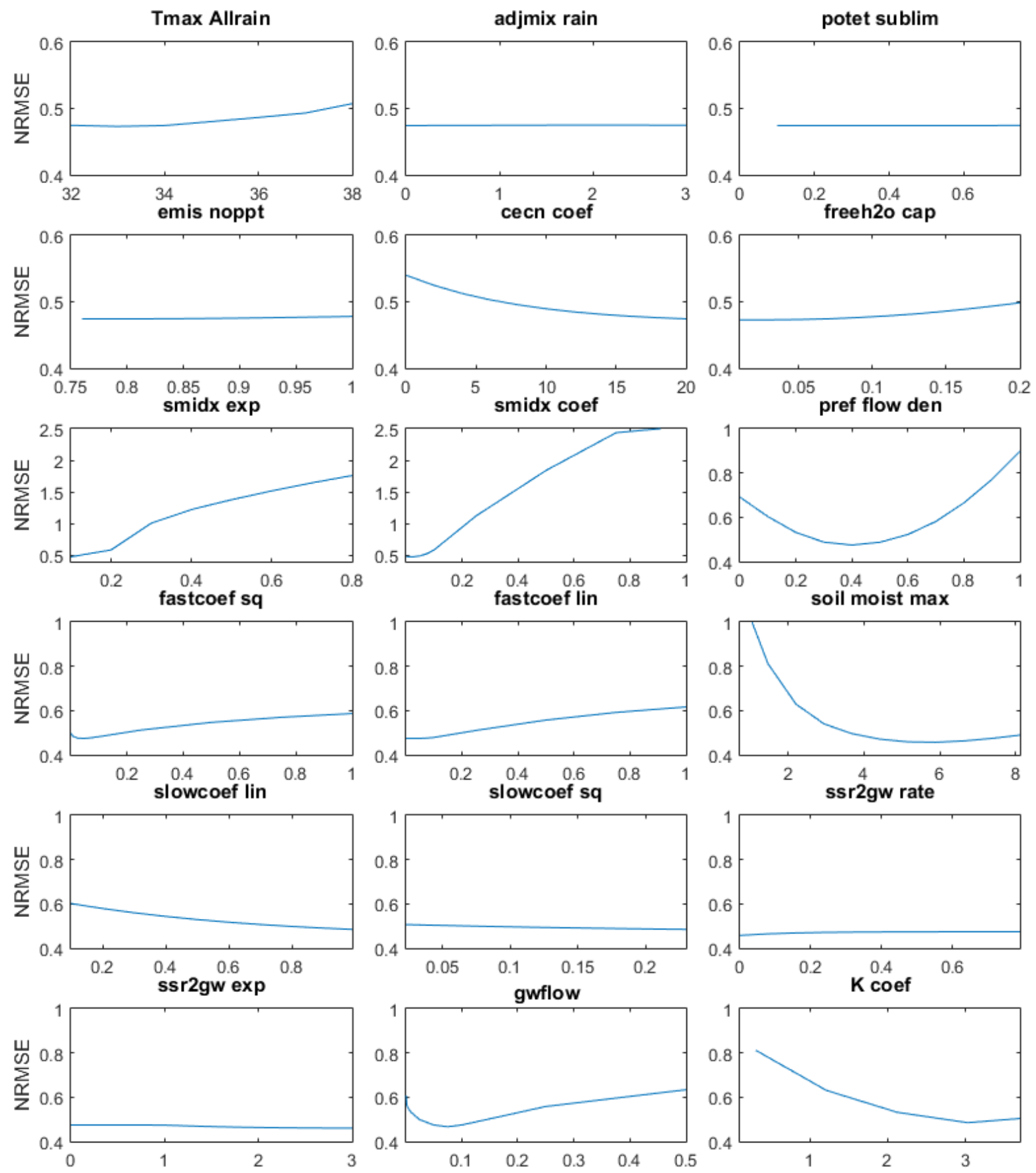

Figure S3 Sensitivity analysis of the calibrated parameters in Big creek watershed. The y-axis values for Soil moist max, slowcoef lin, slowcoef sq and ssrgw rate corresponds to all GRU's average. The $y$-axis values of K_coef corresponds to all segments average. Soil moist max depicts a change from 3 parameters as it was calibrated together with soil rechr max and sat threshold. 


\section{S4. Bias correction validation}
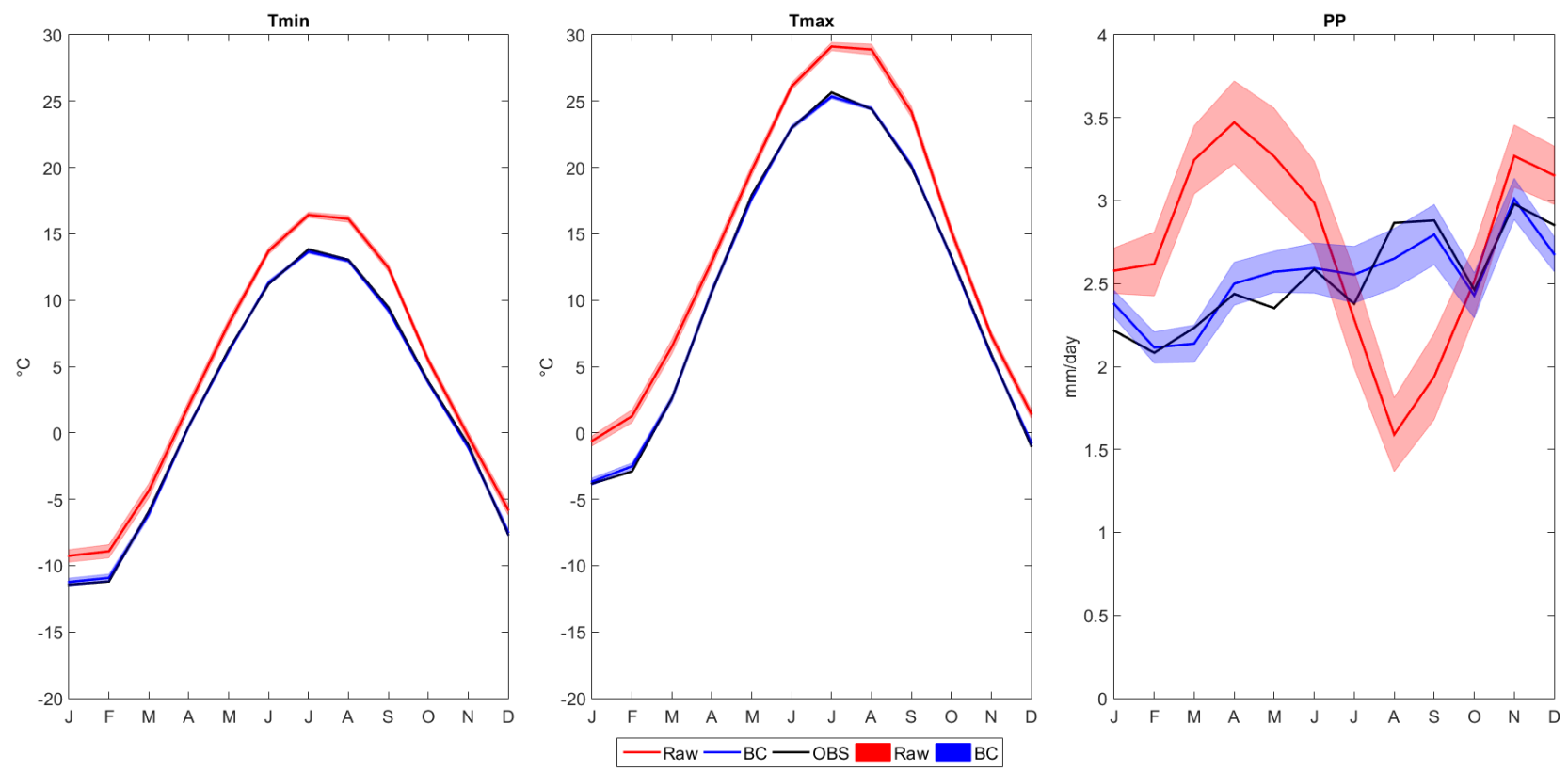

Figure S4 : four-watersheds CRCM5-LE 50-members average and range of monthly temperature and precipitation for raw data (Red), bias corrected data (blue) and NRCANmet (black) 

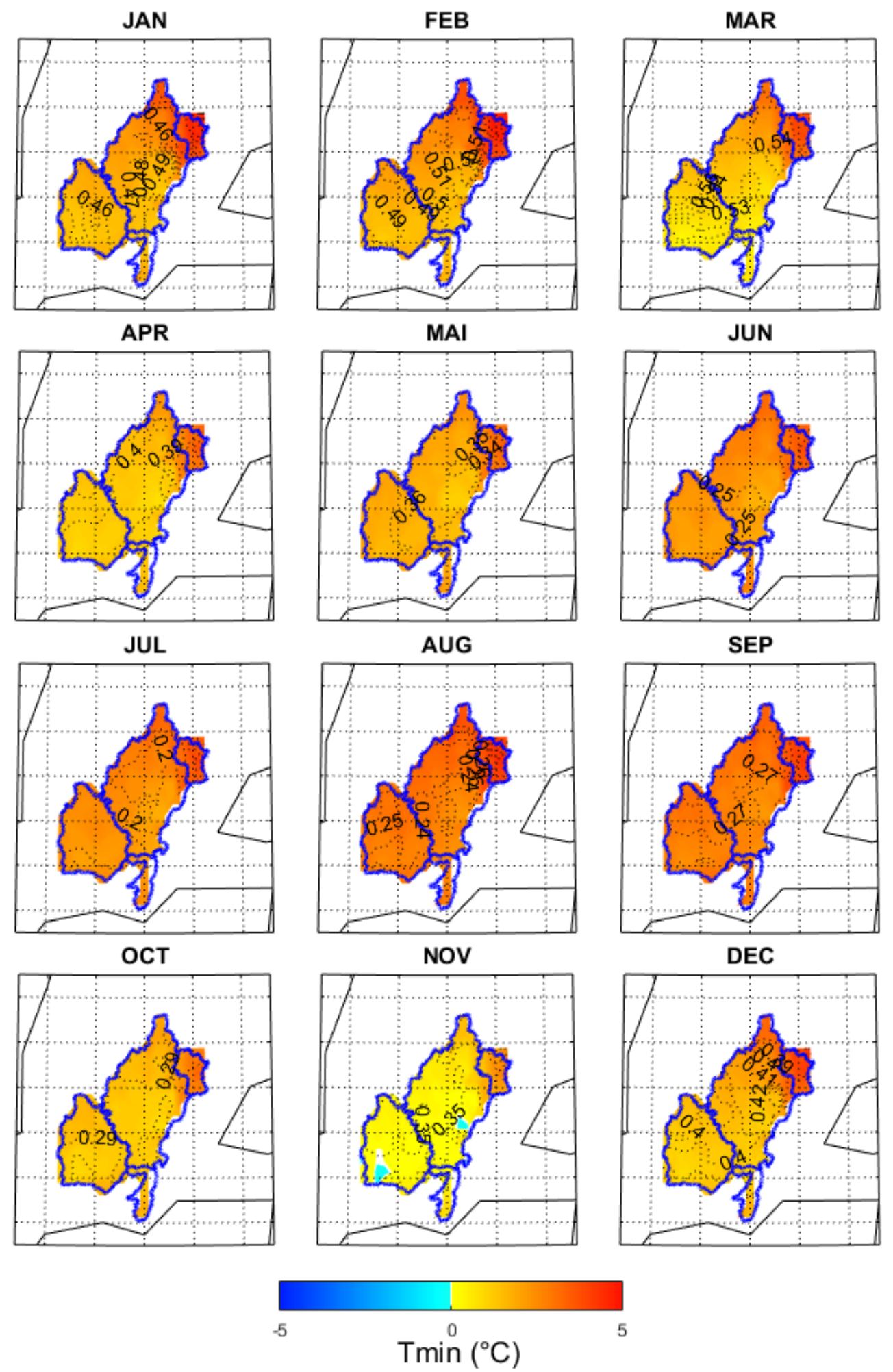

Figure S5. daily minimum temperature difference between raw CRCM5-LE 50-members average and NRCANmet in the 1961-1990 period. The standard deviation between the $\mathbf{5 0}$ members is represented by black numbers (0.01 intervals). 

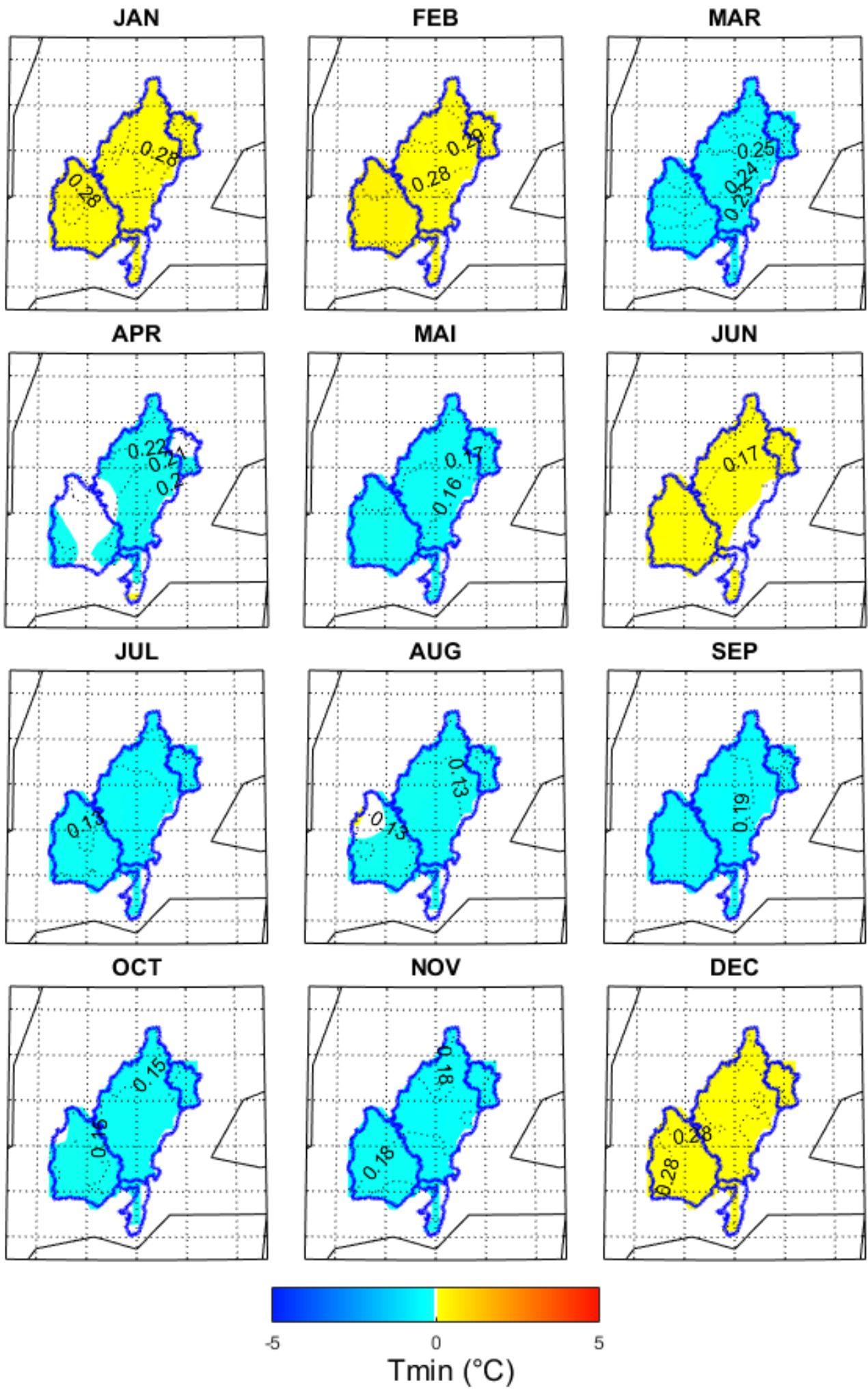

Figure S6. daily minimum temperature difference between bias corrected CRCM5-LE 50-members average and NRCANmet in the 1961-1990 period. The standard deviation between the 50 members is represented by black numbers (0.01 intervals). 

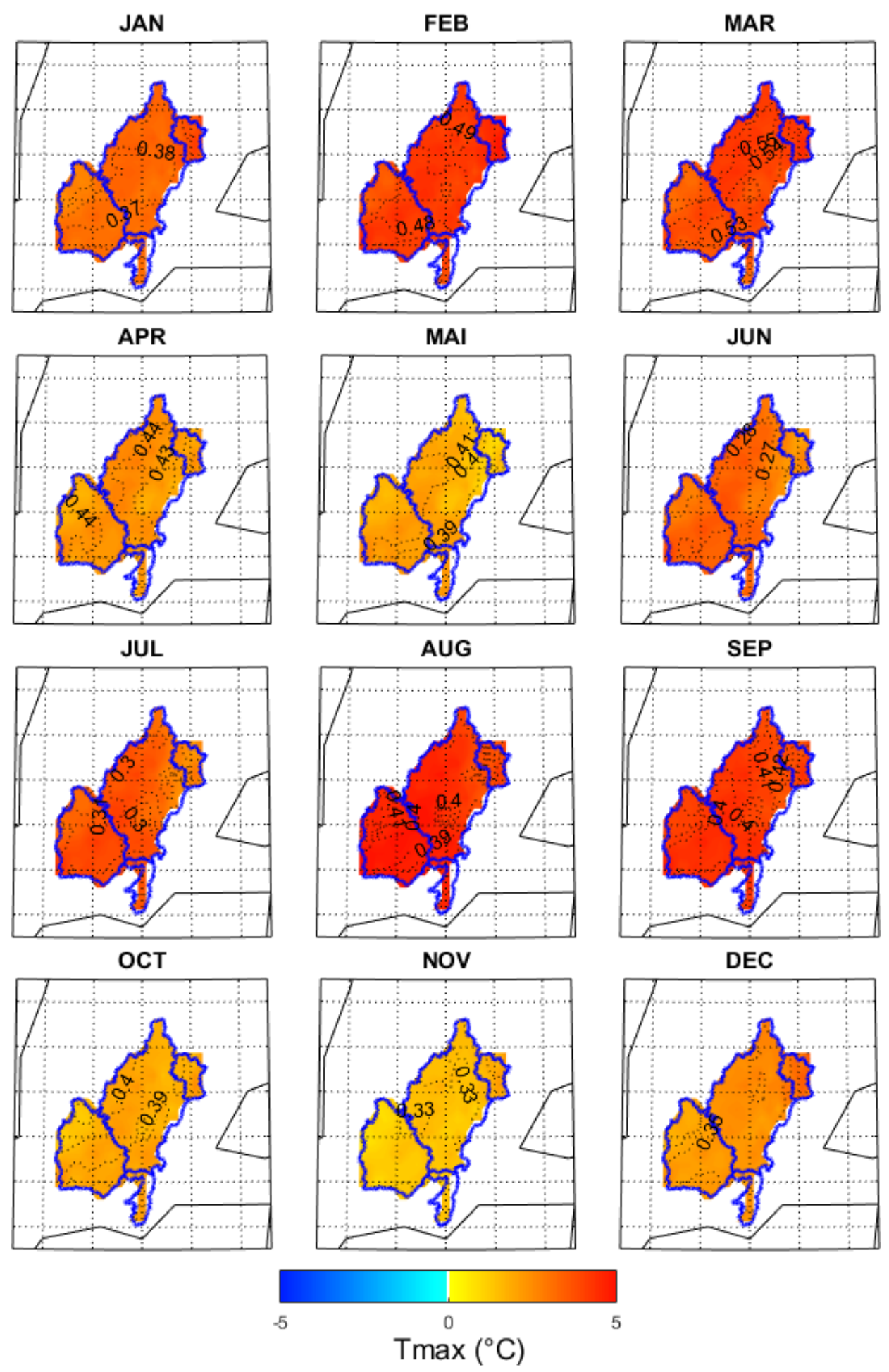

Figure S7 daily maximum temperature difference between raw CRCM5-LE 50-members average and NRCANmet in the 1961-1990 period. The standard deviation between the $\mathbf{5 0}$ members is represented by black numbers (0.01 intervals). 

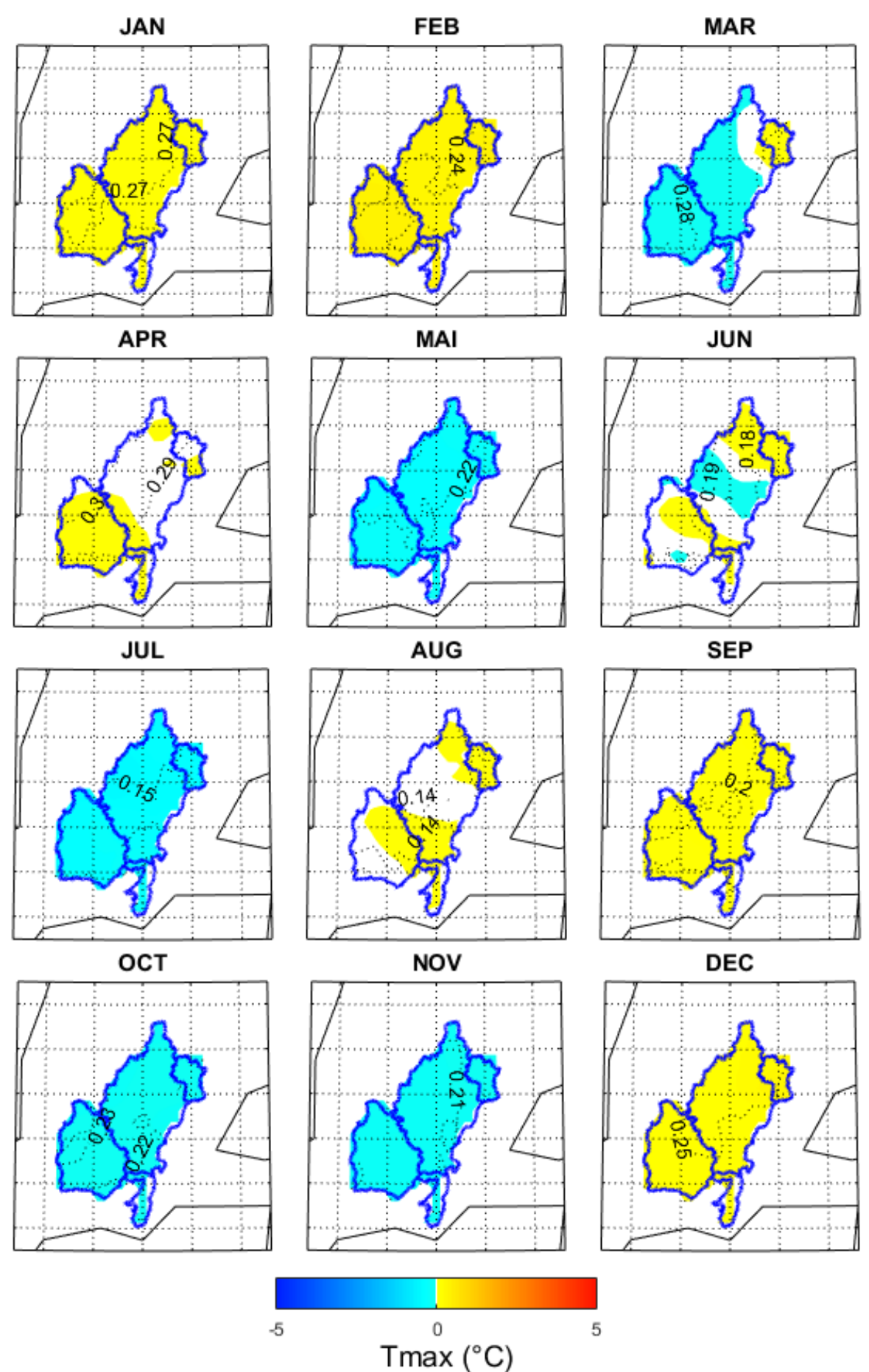

Figure S8 daily maximum difference temperature between bias corrected CRCM5-LE 50-members average and NRCANmet in the 1961-1990 period. The standard deviation between the 50 members is represented by black numbers (0.01 intervals). 

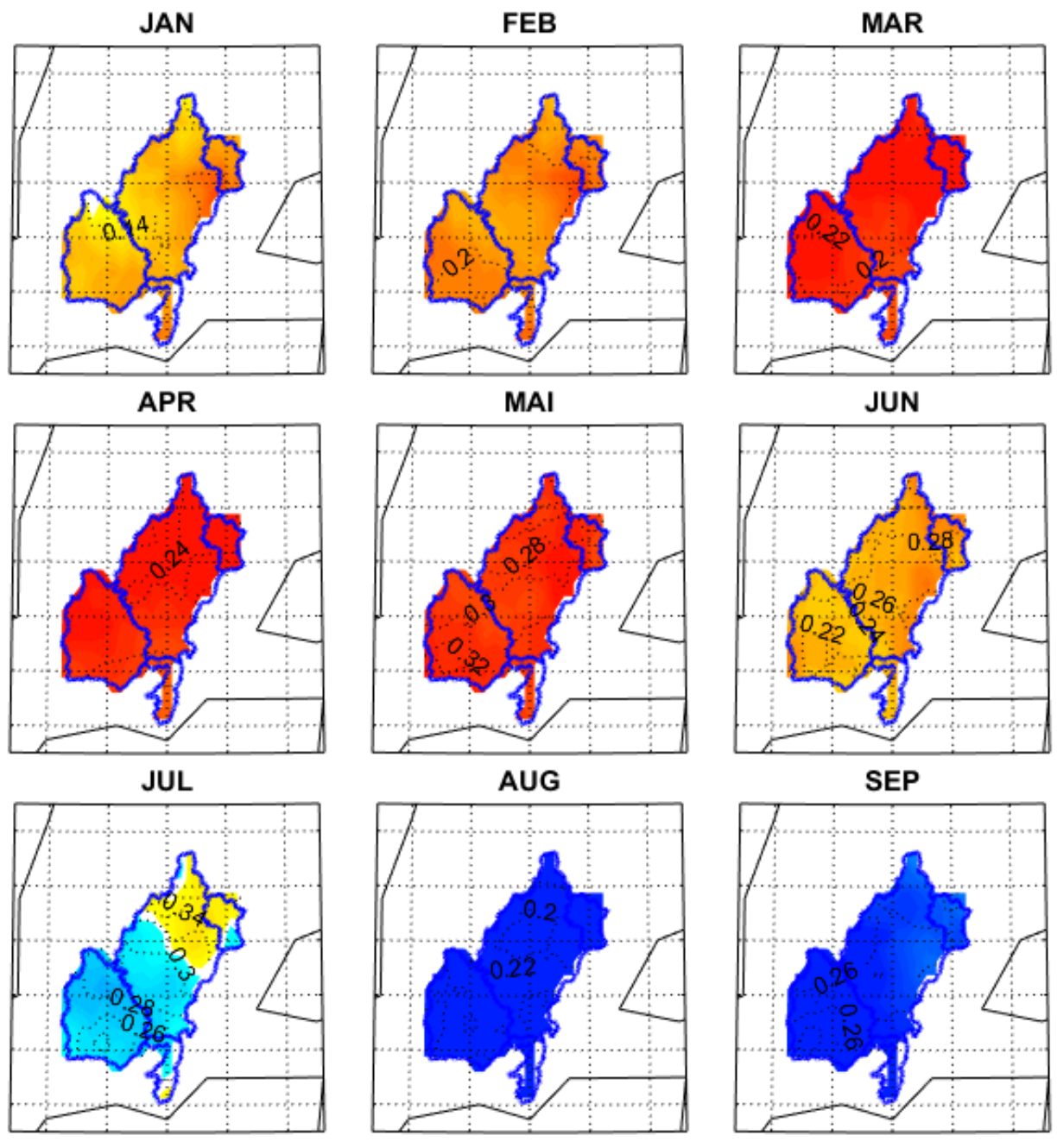

OCT
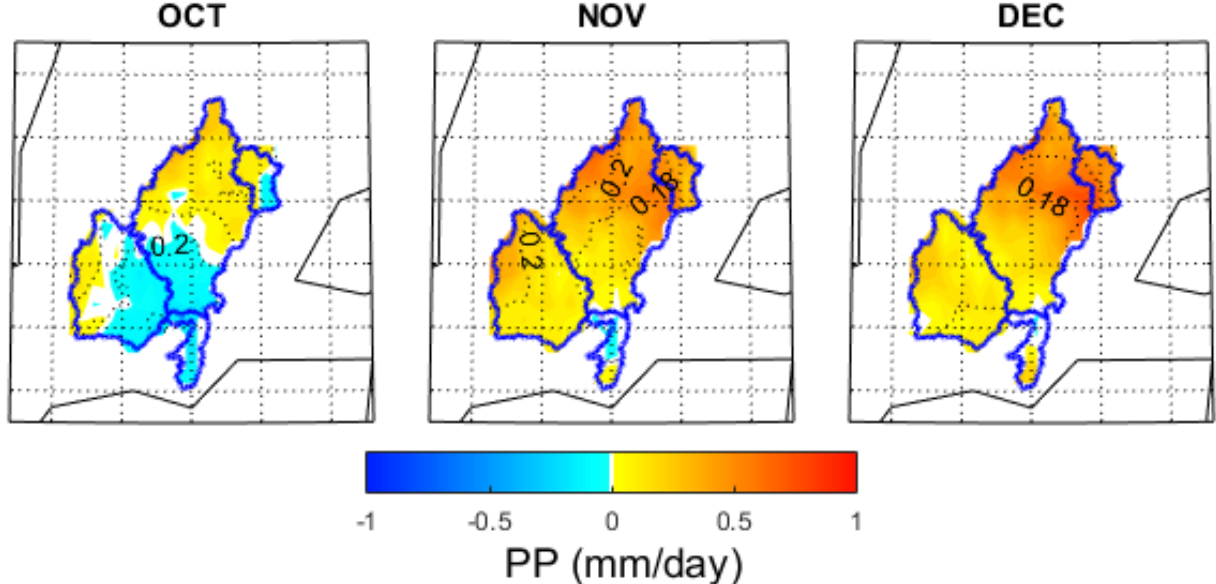

Figure S9 Daily precipitation amount difference between raw CRCM5-LE 50-members average and NRCANmet in the 1961-1990 period. The standard deviation between the 50 members is represented by black numbers $(0.02$ intervals). 

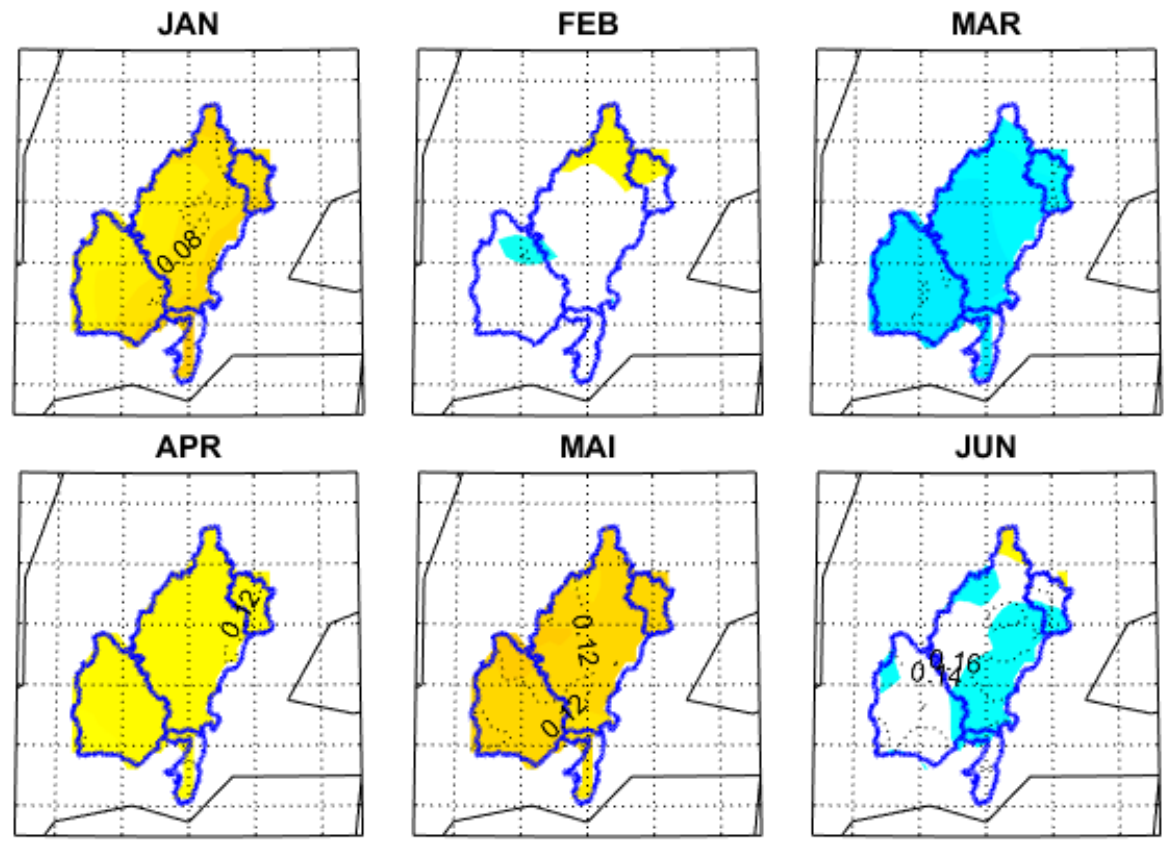

JUL
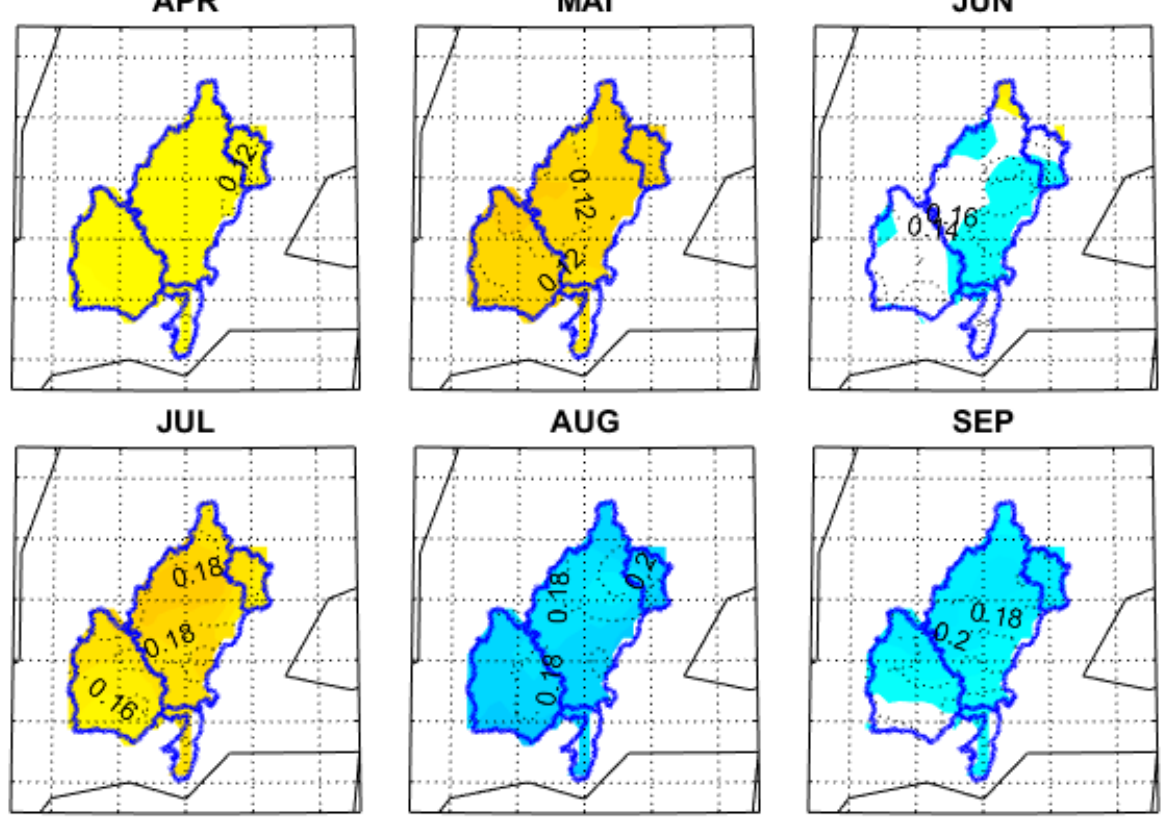

AUG

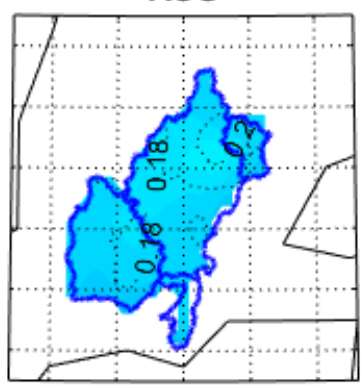

SEP

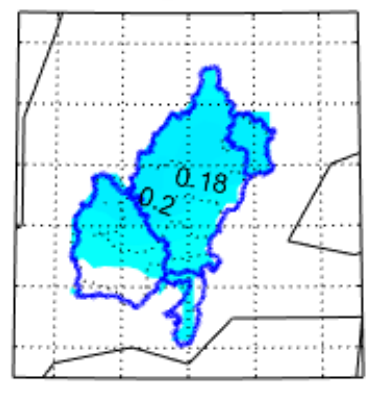

NOV

DEC
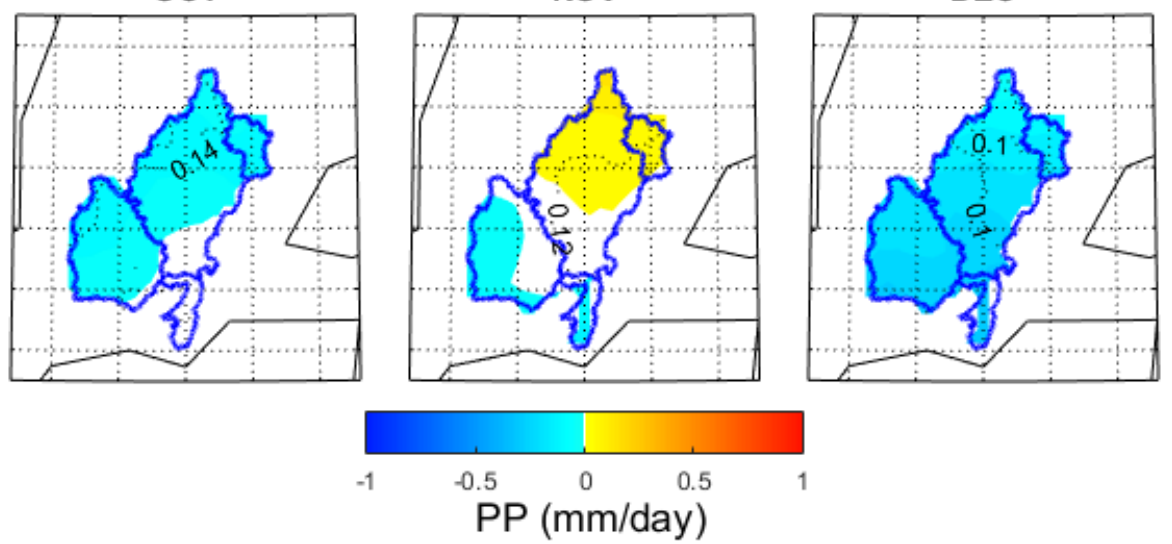

Figure S10 Daily precipitation amount difference between bias corrected CRCM5-LE 50-members average and NRCANmet in the 1961-1990 period. The standard deviation between the 50 members is represented by black numbers (0.02 intervals). 